\title{
AS $\mathbb{A}$ ÇÕES AFIRMATIVAS PARA AFRODESCENDENTES

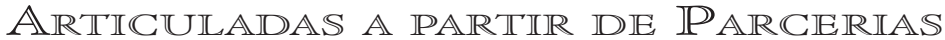

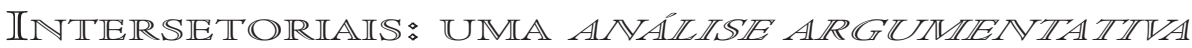 DO CASO GERAÇÃO XXI
}

\section{Rocío Alonso Lorenzo*}

Restrino

(

bjetiva-se com este trabalho aprofundar o conhecimento sobre as parcerias intersetoriais entre Estado, mercado e sociedade civil, a partir da análise argumentativa de um caso, o projeto Geração XXI, a primeira ação afirmativa para jovens negros no Brasil. Este trabalho utiliza as teorias da argumentação, sobretudo a teoria da ação comunicativa de Habermas, para avaliar a validade dos discursos manifestados pelos diferentes parceiros e a capacidade destes de criar "situações dialógicas" que busquem possíveis soluções por vias argumentativas. O trabalho baseia-se numa pesquisa qualitativa que combinou a observação participante com entrevistas semiestruturadas. A conclusão apontará que, apesar de o projeto ter sido bem gerenciado desde o ponto de vista da racionalidade instrumental, houve falhas na construção de um significado aceitável por todos os colaboradores de conceitos-chave - ação afirmativa, gestão da diversidade e responsabilidade social, bem como nos procedimentos de comunicação institucionalizados, que afetaram negativamente os processos e resultados finais do projeto.

Palavras-chave: Ações afirmativas. Afrodescendentes. Parcerias intersetoriais. Ação comunicativa. Análise argumentativa.

Articullating Affirmative Action Policies for Afrordescendaints throurgh Cross-Sector Partmerships: an argummentative anallysis of the Geração XXI case

Abstrealet

$$
\sqrt{1}
$$

he goal of this article is to deepen the knowledge on cross-sector partnerships that are articulated among the State, the market, and civil society, taking as the main focus the argumentative analysis of one case, Geração XXI, the first affirmative action program for black youngsters in Brazil. This paper uses argumentation theory, mainly Haberma's communicative action theory to evaluate the validity of the discourses used by the different partners and the capacity of the latter to create "dialogic situations" that seek possible solutions through argumentative means. The paper is based on qualitative research that combined participant observation with semi-structured interviews. It is concluded that despite the program having been well managed from an instrumental rationality point of view, pitfalls in the construction of a shared meaning acceptable by all the collaborators of key concepts such as affirmative action, diversity-management, and corporate social responsibility, as well in the communication procedures institutionalized, affected the processes and final results of the program negatively.

Keywords: Affirmative action. Afro-descendants. Cross-sector partnerships. Communicative action. Argumentative analysis.

*PhD em Antropologia pela Cornell University. Pós-doutoranda do Departamento de Antropologia da Faculdade de Filosofia, Letras e Ciências Humanas da Universidade de São Paulo - FFLCH/USP, São Paulo/SP/Brasil. Endereço: Av. Profo Luciano Gualberto, 315, Butantã. São Paulo/SP. CEP: 05508-010. E-mail: rocio.a.lorenzo@gmail.com

${ }^{1}$ Agradeço à Wenner-Gren Foundation for Anthropological Research pelo financiamento da pesquisa; aos parceiros, coordenadores(as) e beneficiários do projeto Geração XXI pela colaboração prestada ao longo da pesquisa de campo. 
colaboração entre Estado, mercado e organizações da sociedade civil vem se constituindo em um mecanismo importante para influenciar, complementar e fortalecer as políticas públicas. No contexto de reforma político-administrativa (BRESSER, 1998) e de democracia participativa (SANTOS, 2002), predominantes no Brasil contemporâneo, a intersetorialidade - também chamada de trisetorialidade, por envolver com frequência a colaboração entre os três setores, governo/mercado/ organizações da sociedade civil - torna-se uma "ideia-força" que mobiliza discursos e ações (TEODÓSIO, 2008). A "gestão social" é caracterizada, desse modo, por ser mais "participativa e dialógica", em contraposição à gestão social "tecnoburocrática e monológica", típica do estado do bem-estar (TENÓRIO, 1998: 16; ALVES et al., 2008).

Como outras políticas públicas, sejam de caráter universal ou particularista, grande parte das políticas focalizadas ou ações afirmativas contemporâneas se desenvolve dentro do espaço político da intersetorialidade. Porém, os relacionamentos intersetoriais, no caso específico das ações afirmativas para afrodescendentes, apresentam obstáculos significativos. O principal desafio refere-se a como conciliar a recorrência de governo e mercado às "organizações negras" sem fins lucrativos² para atingir públicos difíceis de alcançar (particularismo) com a tendência daqueles a resistirem à inclusão da questão racial nas suas agendas (universalismo).

Se bem que pesquisas sistemáticas sobre parcerias intersetoriais (AUSTIN, 2001; FISCHER, 2005) têm apontado dificuldade de entendimento, incompatibilidade de culturas organizacionais e falta de diálogo entre as partes como fatores-chave de frustração de grande parte dos projetos sociais gerenciados nesses ambientes institucionais. Esses são aspectos pouco estudados em comparação com a importância dada à racionalidade instrumental da gestão social, tais como o uso eficiente dos recursos transferidos e a expertise dos coordenadores dos programas. Tendo esse contexto como pano de fundo, o objetivo principal deste trabalho é aprofundar o conhecimento sobre as parcerias intersetoriais entre Estado, mercado e sociedade civil, a partir da análise argumentativa de um caso, o projeto Geração XXI , a primeira ação afirmativa destinada a jovens negros no país. Para tanto, avalia-se a validade dos discursos manifestados pelos diferentes parceiros, assim como a capacidade destes de criar "situações dialógicas" que busquem possíveis soluções dos conflitos por vias argumentativas.

De um modo geral, parte-se da abordagem da análise argumentativa das políticas públicas, principalmente da teoria da ação comunicativa desenvolvida por Jürgen Habermas (2010). Um dos principais objetivos da teoria da ação comunicativa é elaborar um conceito de racionalidade comunicativa que se contraponha ao de racionalidade orientada a fins, desenvolvido por Max Weber em Economia e sociedade (2009 [1956]). De acordo com Freitag (2005), na visão de Habermas, Weber se confronta com um paradoxo que não consegue resolver. Isto é, a razão instrumental, "ao abandonar sua origem religiosa, perde de vista sua intenção original de liberar o homem (...) acabando por subjugá-lo ao mito da modernidade" (FREITAG 2005, p. 40). Nas palavras de Habermas (2010, p.271) , " $^{2}$ ética protestante põe em andamento o capitalismo, mas sem poder garantir as condições de sua própria estabilidade como ética". Habermas, contudo, permanece otimista, e, como Freitag (2005) esclarece, o autor considera que uma parte dessa racionalidade instrumental monológica orientada a fins teria se concretizado em práticas quotidianas sob a forma de uma reserva de

²Organizações da sociedade civil que têm como principal foco de atuação a população negra ou afrodescendente. O leitor perceberá que ao longo do texto utilizam-se os termos negro e afrodescendente indistintamente. Contudo, vale esclarecer que enquanto o termo afrodescendente identifica os descendentes de escravos, o termo negro tipifica a cor da pele e corresponde à categoria utilizada pelo IBGE, que agrega pardos e pretos sob a categoria negro. Para o título deste artigo preferiu-se o termo afrodescendente ao em vez de negro por remeter aquele a uma missão reparatória dessas políticas e por desfrutar de uma maior aceitação na população brasileira como um todo.

${ }^{3}$ Todas as citações que aparecem neste artigo do livro de Habermas Teoría de la acción comunicativa (2010) foram traduzidas pela autora do espanhol para o português. 
razão comunicativa, que deve ser recuperada em uma situação de fala ideal entre interlocutores competentes, isenta de coerção externa e interna. O objetivo fundamental da ação comunicativa seria assegurar o esclarecimento dos pontos de vista, desvendar a verdade e obter consenso, coordenados através de determinados atos de fala com pretensão de validade (SIEBENEI CHLER 1989). A contraposição proposta por Habermas (2010) entre racionalidade estratégica orientada ao êxito e racionalidade comunicativa orientada ao entendimento é extremamente útil para indagar as condições do entendimento possível no contexto das parcerias intersetoriais.

O projeto Geração XXI foi lançado em 1999, como resultado de uma parceria intersetorial entre a Fundação BankBoston (hoje Fundação Itaú), o Geledés - Instituto da Mulher Negra e a Fundação Palmares, entidade ligada ao Ministério da Cultura. O projeto selecionou 21 jovens negros como alvo da ação, sendo 12 garotas e nove rapazes entre 13 e 15 anos, oriundos de escolas públicas de São Paulo. O objetivo era garantir a esses jovens condições plenas para seu autodesenvolvimento: boas escolas, acesso a bens culturais, boa alimentação e atenção à saúde, até que concluíssem a universidade. Além do acompanhamento da aprendizagem dos jovens, o projeto visou influenciar as políticas públicas do governo, a partir da mobilização e sensibilização da rede escolar por meio de discussões sobre cidadania e diversidade. O Geração XXI, dada a sua novidade, foco, investimento e duração, veio representar uma experiência de política social pioneira no Brasil. No ano de 2004, momento em que iniciei a pesquisa de campo, projetos inspirados pelo Geração XXI estavam sendo formulados ou já implementados em cinco subsidiárias de multinacionais: Monsanto, Xerox, Colgate-Palmolive, Unilever e Philips.

O estudo do caso Geração XXI formou parte de um projeto maior, de pesquisa de doutorado, desenvolvido durante um ano e meio, entre 2004 e 2005, cujo objetivo principal foi analisar as políticas de diversidade e/ ou ações afirmativas para afrodescendentes numa rede de empresas em São Paulo. Durante a última fase da pesquisa de campo, que durou três meses, foram realizadas quinze entrevistas em profundidade, com parceiros e beneficiários do projeto, incluindo gerentes da Fundação BankBoston, coordenadores(as) do Geledés e 11 jovens beneficiários dentre os 21 que participaram no projeto. Além das entrevistas e da participação em encontros, reuniões e outros eventos vinculados ao projeto, foram realizadas visitas semanais à sede do projeto, onde parceiros e beneficiários se encontravam regularmente.

O presente trabalho incorpora, em primeiro lugar, uma fundamentação teórica do conceito habermasiano de ação comunicativa, e como este pode elucidar limitações importantes que a própria gestão social envolve quando percebida só através da lente da racionalidade instrumental. Em segundo lugar, o conceito de parceria intersetorial é definido e contextualizado. Seguidamente, salientam-se as contingências político-institucionais que deram lugar à formulação de políticas específicas para a população afrodescendente no Brasil, assim como dados relevantes de desigualdade racial que justificariam tais políticas. Finalmente, o caso do projeto Geração XXI é avaliado a partir da perspectiva da análise argumentativa habermasiana, descrevendo a metodologia de pesquisa utilizada, mostrando os depoimentos dos entrevistados e, por fim, apresentando os principais questionamentos e resultados.

\section{A Amålise Argurnerntarival das Politicas Priblicals}

A análise argumentativa das políticas públicas se desenvolve na década de 80 , em alguns círculos acadêmicos anglo-saxões, como reação à denominada análise racional custo-benefício, predominante desde a Segunda Guerra Mundial. Grosso modo, as teorias da argumentação, no âmbito da administração pública, são oriundas da tradição pluralista da ciência política - em contraposição à tradição tecnocrática - e de debates epistemológicos pós-modernos mais recentes sobre a filosofia e a sociologia da ciência, como os levantados pelo chamado linguistic turn. Proclamada pelo próprio Habermas (FREITAG, 2005), a guinada linguística implica uma reviravolta paradigmática da filosofia positiva para a pragmática da linguagem, ou seja, a teoria da verdade 
consensual e a ética discursiva baseada na legitimação por vias argumentativas. A ideia principal da lógica pragmática da argumentação é que os discursos manifestados pelas pessoas não refletem só uma realidade objetiva ou uma identidade subjetiva, mas o que é verbalizado na hora, tendo presente uma "audiência prática" (WALTON, 1989). É nesse sentido que a palavra discurso - diskurs - adquire na teoria da ação comunicativa de Habermas um forte sentido de "discussão" (ALMEIDA, 1985).

Os teóricos da argumentação coincidem na crítica ao racionalismo instrumental perante as políticas contemporâneas de planejamento. De acordo com Majone (1989, p. 23), a metodologia do "decisionismo", baseada no racionalismo instrumental, "restringe o papel da razão ao descobrimento de meios apropriados para fins determinados", a partir do uso de modelos matemáticos ou outras técnicas objetivas de análise. Ao privilegiar a análise sistemática prévia de alternativas para a formulação de planos de ação, a racionalidade instrumental relega valores, critérios, juízos e opiniões ao domínio da irracionalidade ou do subjetivo. Embora sejam várias as correntes filosóficas que têm influenciado os defensores da argumentação como ferramenta analítica das políticas públicas (NELSON, MEGILL; MCCLOSKEY, 1987; MAJ ONE, 1989; FISCHER; FORESTER, 1993), aqui, a teoria da ação comunicativa de Habermas receberá foco por ter um componente utópico de democracia radical, no sentido de democracia deliberativa, voltada à institucionalização de procedimentos de comunicação simétricos (igualitários) como força legitimadora da vontade comum (HABERMAS, 2003). A maneira como as parcerias intersetoriais são concebidas em contextos de democracia participativa como o brasileiro aproxima-se do tipo ideal de situação de fala habermasiano, voltado para o entendimento e o consenso. Contudo, a suposição de uma "situação de fala ideal" que especifica uma norma de comunicação simétrica de acordo com a qual os interlocutores devem estar livres de constrangimentos para alcançar o entendimento pleno (ver CARDOSO DE OLI VEI RA, 2000), como será mostrado no caso Geração XXI, raramente se encontra em "estado puro" no mundo empírico.

O pressuposto central da teoria da ação comunicativa gira em torno da competência comunicativa enquanto capacidade fundamental da interação humana e da significação da vida e da realidade. A linguagem assume papel central como medium regulador do comportamento e do entendimento mútuo, assim como "critério do processo de emancipação da humanidade" (SIEBENEICHLER, 1989, p. 50). Entender-se, na visão de Habermas (2010, p. 354), significa que "se produz entre (ao menos) dois sujeitos capazes de linguagem e ação um acordo".

Como apontado na introdução do presente trabalho, na visão de Habermas (2010), a ação instrumental, institucionalizada de forma quase hegemônica nas sociedades modernas contemporâneas, precisa ceder lugar à ação comunicativa, presente no início dos processos de modernização da sociedade europeia e frágil sobrevivente nos "nichos" do "mundo vivido" dessas sociedades.

A ação comunicativa baseia-se num processo cooperativo de interpretação em que os participantes se referem simultaneamente a algo no mundo objetivo, no mundo social e no mundo subjetivo mesmo quando na sua manifestação só sublinhem tematicamente um destes três componentes (HABERMAS 2010, p. 598, grifos do autor).

Habermas (2010) estabelece uma pragmática formal, baseada na classificação de "tipos puros de interação linguisticamente mediada" que possam desvelar as condições do entendimento possível. Inspirado na classificação de Austin de atos de fala em locucionários, ilocucionários e perlocucionários, Habermas (2010, p.373), no entanto, considera que aquele teria se limitado à perspectiva do falante em relação a um mundo objetivo, sem levar em conta que "os propósitos ilocucionários dos atos de fala (fazer algo dizendo algo) se conseguem por meio do reconhecimento intersubjetivo de pretensões de poder ou de pretensões de validade". O resultado dessa reflexão leva à seguinte classificação de atos de fala (HABERMAS, 2010, p.374), dos quais o primeiro é orientado ao sucesso, enquanto os três últimos são orientados ao entendimento:

a) imperativos (perlocuções): o falante deve mobilizar o ouvinte para realizar algo no mundo objetivo. Os imperativos só podem ser criticados sob o ponto de vista de se a ação exigida é factível ou não. A rejeição de um imperativo significa a rejeição de uma pretensão de poder; 
b) constatativos: o falante refere-se a algo no mundo objetivo e a negação de tais emissões implica que o ouvinte questione a pretensão de verdade que o falante pretende com a sua afirmação;

c) regulativos: o falante refere-se a algo no mundo social comum, no sentido de estabelecer uma relação interpessoal que seja reconhecida como legítima. A negação de tais emissões significa que o ouvinte questiona a retidão normativa (conformidade com as normas sociais) que o falante pretende com a sua ação;

d) expressivos: o falante refere-se a algo no seu mundo subjetivo, no sentido de desvelar ante um público uma vivência a que ele tem acesso privilegiado. A negação de tais emissões significa que o ouvinte põe em dúvida a pretensão de veracidade (sinceridade) que o falante pretende fazer de si mesmo.

Na interpretação de Freitag (2005, p.44) da obra de Habermas, a ação comunicativa se desenvolve dentro do mundo vivido "transfundo de saber implícito que penetra os processos cooperativos de interpretação". O mundo vivido é, pois, simultaneamente, lugar de reprodução sociocultural e socialização e de questionamento das "pretensões de validade" dos atores em relação aos três mundos formais: o objetivo, o social e o subjetivo. O que sempre foi taken for granted pode ser posto em questão numa situação de ação comunicativa e debatido pelo grupo, que só respeitará o que tiver sido consensualmente acordado.

A ação comunicativa vai sendo gradualmente substituída pelos mecanismos do dinheiro e do poder, ou seja, pelo sistema. O mundo vivido passa por uma "disjunção" do sistema e é "colonizado" por mecanismos de integração sistêmicos. A teoria da ação comunicativa tem, pois, como tarefa principal denunciar esses processos que levam a situações de comunicação "sistematicamente distorcidas", de forma inconsciente (autoengano) ou de forma consciente (manipulativa). Cabe à teoria da ação comunicativa promover a reunificação conceitual e prática do mundo vivido e do sistema numa concepção globalizante de sociedade, em que estejam assegurados os processos de reprodução material e cultural pela cooperação e pelo consenso dos seus membros. Essa reintegração pressupõe a "descolonização" do mundo vivido, i.e., a expulsão da razão instrumental e a consolidação da ação comunicativa (FREITAG, 2005).

Conforme será exposto adiante, apesar dos resultados positivos, "distorções comunicativas" fundamentais (inconscientes e manipulativas) comprometeram a possibilidade de um "entendimento pleno" entre os parceiros atuantes no Geração XXI, dada a participação desequilibrada entre as partes, as diferentes expectativas direcionadas aos objetivos dos programas, assim como a predisposição geral dos diferentes parceiros (interlocutores improváveis até pouco tempo atrás) a atitudes preconceituosas e à desconfiança mútua.

\section{IHIistórrico dlas Parreerials Intersetorianis}

Parceria, num sentido amplo e sob o ponto de vista da empresa, é "toda forma de colaboração ou trabalho conjunto que a empresa mantenha com outras organizações da sociedade e do Estado para realizar suas práticas de atuação social" (FISCHER, 2005 , p. 12). A aliança social estratégica, termo utilizado com frequência como sinônimo de parceria, distingue-se desta. Enquanto

a lógica da parceria é a da intercomplementariedade de recursos e capacidades entre organizações parceiras, a da aliança é a de organizações que poderiam atuar de forma independente diante de uma determinada questão, mas decidem fazê-lo conjuntamente, motivadas pela consciência da magnitude e complexidade da ação a ser empreendida. (NOLETO, 2004, p. 15).

Ou seja, as alianças sociais estratégicas seriam "relações de parceria que adquirem características de entrosamento mais profundo entre organizações aliadas" (AUSTIN, 2001). Essa visão da aliança estratégica parte de um pressuposto 
de racionalidade instrumental, uma vez que “(...) as iniciativas de desenvolvimento social buscaram formas organizativas que aumentassem a eficiência e assegurassem a eficácia de suas ações" (FISCHER, 2005, p. 12). O conceito de aliança estratégica, segundo Fischer (2005), seria bastante inovador para o cenário das relações de cooperação organizacional no Brasil. O projeto Geração XXI foi concebido, oficialmente, como aliança estratégica, mas, na prática, os colaboradores do projeto utilizavam o termo parceria.

No Brasil, o papel do Estado no estabelecimento de um claro marco legal que regule o terceiro setor tem sido fundamental para o desenvolvimento das parcerias intersetoriais. O termo "parceria" adquiriu grande popularidade, principalmente, em razão do sucesso das propostas da Comunidade Solidária (termo rebatizado de Comunitas, após o final do governo FHC), que, desde 1995, vem disseminando o conceito e estimulando a aproximação de empresários, governos e lideranças comunitárias na solução de problemas sociais (FISCHER, 2005). Foi no âmbito da Comunidade Solidária que a Lei 9790 - Lei das Oscips, de 1999 - foi estabelecida, a qual: “Dispõe sobre a qualificação de pessoas jurídicas de direito privado, sem fins lucrativos, como Organizações da Sociedade Civil de Interesse Público, institui e disciplina o Termo de Parceria, e dá outras providências". Diferentemente dos convênios e dos acordos, o termo parceria foi proposto no sentido de se criarem "instrumentos mais transparentes e democráticos para estimular os projetos e atividades das organizações sem fins lucrativos" (ALVES; KOGA, 2006, p. 220). Embora o Geledés (Instituto da Mulher Negra) - como muitas outras ONGs - tenha resistido até hoje a constituir-se em uma Oscip, por razões que não cabem a este trabalho, o estatuto do Geração XXI, porém, foi concebido dentro do marco legal das Oscips.

O conceito de parceria intersetorial é articulado, assim, num novo contexto de "gestão social" contraposto à gestão estratégica, “( ...) na medida em que tenta substituir a gestão tecnoburocrática, monológica, por um gerenciamento mais participativo, dialógico, no qual o processo decisório é exercido por meio de diferentes sujeitos sociais" (TENÓRIO, 1998, p. 16). Nas democracias participativas, a "ação pública" passa a funcionar num ambiente "híbrido" "que se caracteriza pelas conexões entre organizações distintas, mas cujos destinos estão 'positivamente correlacionados'" (ALVES et al., 2008, p. 62). Contudo, como Fischer (2005) aponta,

as organizações que devem se aliar são muito diferentes entre si por pertencerem a diversos setores, por terem natureza diversa em sua origem e por estarem posicionadas em diferentes distâncias em relação ao objetivo de desenvolvimento social que motivou a parceria. (FISCHER, 2005, p. 12).

Como o leitor poderá comprovar na parte final deste trabalho, os parceiros do Geração XXI não só diferem nos seus "mundos vividos", oriundos de identidades subjetivas e culturas organizacionais distanciadas, mas, também, discordam sobre os assuntos que devem ser tematizados e consensualmente acordados.

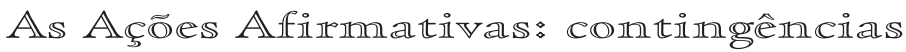 Polliticorinstituriona is}

Uma das mais evidentes "distorções comunicativas" do projeto Geração XXI foi não ter alcançado um "acordo pleno" em torno de um significado aceitável por todos os parceiros de conceitos-chave, como ação afirmativa, gestão da diversidade e responsabilidade social empresarial. Parte do desacordo deve-se ao fato de a sociedade brasileira, no geral, e de o mundo corporativo, em particular, não reconhecer o racismo como um problema social legítimo, digno de um tratamento diferenciado; apesar da questão do racismo ter entrado de maneira decisiva no âmbito do Estado a partir da Constituição de 1988, data que, além da re-democratização, representa o centenário da abolição da escravidão. Desde então, dois eixos fundamentais norteiam a maneira como o Estado brasileiro aborda a questão racial: a condenação do racismo e a promoção da identidade cultural afro-brasileira (HASENBALG; SILVA, 1992). 
Contudo, apesar da juridificação do racismo e da vontade do Estado de proteger a cultura afro-brasileira, as ações afirmativas para negros não se concretizaram até o governo de Fernando Henrique Cardoso.

Entende-se por ação afirmativa: “[q]ualquer programa ou ação pública ou privada que providencia ou busca providenciar oportunidades ou outros benefícios a pessoas com base, entre outros critérios, em sua pertença a um grupo ou grupos específicos" (GUI MARÃES, 1996, p. 238, tradução da autora). Em pesquisa desenvolvida pelo IPEA (J ACCOUD; BEGHIN, 2002) sobre as políticas de ação afirmativa durante o governo FHC, foram identificados 40 programas e ações em instituições governamentais. A partir de 2003, o governo Lula garantiu a continuidade dos programas iniciados durante o governo FHC, assim como a implementação de outros programas e ações. Em 2003, criou-se, no plano Executivo Federal, a SEPPIR - Secretaria Especial para a Promoção da I gualdade Racial, a qual atua de maneira transversal em várias áreas, destacando- se a da educação (implementação da Lei 10.639/03, que torna obrigatório o ensino da história da África e das culturas afro-brasileiras nas escolas de ensino fundamental e médio), a da saúde direcionada à população negra, a da agenda social quilombola (comunidades remanescentes de quilombos) e a da capacitação profissional.

Apesar da transversalidade das ações afirmativas, nenhum tema tem ganhado tanto destaque na última década como a reserva de cotas raciais nas instituições de ensino superior. Segundo Heringer e Ferreira (2009), dentre as 224 instituições públicas de ensino superior que existem no Brasil, setenta e nove promovem algum tipo de ação afirmativa. No ensino superior privado, as políticas afirmativas se desenvolveram por meio do Programa Universidade para Todos - ProUni, institucionalizado em janeiro de 2005, que permite a oferta de um grande número de bolsas de estudos mediante isenção de impostos às universidades que aderem ao programa do Governo Federal.

No setor privado, ações afirmativas para afrodescendentes começaram a ser implementadas em meados dos anos 90, articuladas sob o guarda-chuva da "gestão da diversidade cultural" (FLEURY, 2000). Durante a primeira metade de 2000, a partir da movimentação das ONGs negras e da influência do movimento da responsabilidade social empresarial, as ações afirmativas para afrodescendentes se expandiram a um número maior de empresas de diferentes nacionalidades e porte (ver MYERS, 2003). Recentemente, ações afirmativas foram implementadas em vários setores da atividade econômica, principalmente no bancário, como resposta à atuação do Ministério Público do Trabalho (MPT), que criou o "Programa de Promoção da I gualdade de Oportunidade para Todos", cujo objetivo é "atuar extrajudicialmente ou judicialmente no combate às discriminações de gênero e raça no mercado de trabalho" (BARBOSA, 2009, p. 8). Contudo, uma pesquisa desenvolvida pelo Instituto Ethos de Responsabilidade Social e o IBOPE, aplicada nos anos 2003, 2005, 2007 e 2010, mostrou que, entre as empresas pesquisadas dentre as 500 maiores empresas do Brasil, o percentual daquelas que investiram em programas para melhorar a capacidade e qualificação dos negros passou de 1\% em 2003, a 4\% em 2005, a 16\% em 2007, caindo para 9\% em 2010. Outra pesquisa, baseada numa amostra de 385 empresas em vários estados do Brasil, revelou que de $85 \%$ das que executavam seus programas por meio de alianças intersetoriais, só em $1,8 \%$ dos casos o público de atuação social das empresas eram negros, comparado com 2,6\% índios, 6,5\% mulheres e 79,0\% crianças e adolescentes (FISCHER, 2005, p. 10-11).

No âmbito do governo do Estado de São Paulo, destaca-se a criação inédita no Brasil, em 2006, do Selo Paulista da Diversidade, o qual outorga reconhecimento público a entidades públicas, privadas ou da sociedade civil que valorizem a diversidade étnico-racial e de gênero. Entre as organizações negras paulistas que mais têm atuado diretamente em colaboração com governo e empresas privadas na implementação efetiva de políticas e programas de ação afirmativa, destacam-se, entre outras: Geledés, Educafro, Afrobras, CEERT e Integrare. O Geledés tem sido pioneiro na área dos direitos humanos, principalmente dos direitos da mulher negra, assim como no desenvolvimento de projetos de ação afirmativa para jovens negros como o Geração XXI, em parceria com instituições públicas e privadas. Educafro e Afrobras têm se destacado pela congregação de centenas de núcleos de preparação de jovens 
negros e carentes para o vestibular. O CEERT - Centro de Estudos das Relações de Trabalho e Desigualdades tem sido particularmente ativo na promoção da igualdade racial e de gênero no mercado de trabalho. O Integrare - Centro de Integração de Negócios tem concentrado as suas ações na área do empreendedorismo negro e dos negócios inclusivos.

As organizações negras paulistas, no geral, apesar dos obstáculos enfrentados, têm revelado um pioneirismo excepcional na articulação de ações afirmativas para afrodescendentes. Ademais, por ser a região economicamente mais ativa do país, muitas experiências iniciadas em São Paulo são depois replicadas em outras cidades e estados.

No âmbito das ciências sociais, a denominada "escola paulista" teve um papel desmitificador no reconhecimento da discriminação racial no Brasil. Os estudos sociológicos desenvolvidos pela "escola paulista" e financiados pela UNESCO (FERNANDES, 1969; CARDOSO; IANNI, 1960; BASTIDE; FERNANDES, 1971) enfocaram, principalmente, as relações verticais e a desigualdade racial, em contraste com os estudos da chamada "escola baiana" que seguiam a ênfase de Gilberto Freyre (2002) dada às relações horizontais ou integração dos "grupos minoria" na sociedade (ver GUIMARÃES, 1999, p. 71-91; TELLES 2003, p. 20-21).

Desde os anos 90, um corpo imenso de dados estatísticos produzido por instituições nacionais de pesquisa tem constituído prima facie evidência da repetição de padrões de desigualdade racial ao longo de várias gerações. Baseado em dados do IBGE de 1999, um relatório publicado pelo IPEA (HENRIQUES, 2001) mostrou alguns dados relevantes, entre os quais: os brasileiros negros compõem $64 \%$ da população pobre brasileira, comparado com 34\% de brancos pobres; de cada 10 pessoas no segmento mais pobre, segundo a distribuição de renda no país, 8 são negras; a renda per capita dos brancos é quase $20 \%$ mais alta do que a renda per capita dos negros; quase a metade da população negra adulta acima dos 25 anos pode ser considerada analfabeta funcional, ou seja, adultos com menos de quatro anos de escola; e o padrão de desigualdade educacional de 2,3 anos de diferença entre os dois grupos tem persistido durante três gerações.

Em resumo, apesar do ambiente político altamente participativo propiciado pela Constituição de 1988, da questão do racismo ter entrado de maneira decisiva na agenda dos governos democráticos recentes, da disponibilidade cada vez maior de dados relevantes de desigualdade e discriminação racial e da proliferação de políticas afirmativas destinadas à população negra ou afrodescendente, estas não dispõem da legitimidade que seria esperada num contexto político supostamente tão favorável, se levadas em conta as fortes opiniões contrárias de uma grande parte de setores dominantes da sociedade brasileira, entre eles a mídia.

\section{Metodologia de Pesqurisa}

Como indiquei no início, o caso Geração XXI formou parte de uma pesquisa de campo mais ampla que teve como objetivo principal mapear e analisar as políticas de diversidade e ações afirmativas para negros numa rede de empresas atuantes no município e regiões periféricas de São Paulo. Entre julho de 2004 e janeiro de 2005, visitei 15 empresas, sendo sete multinacionais e oito brasileiras (dentre estas últimas, duas eram de grande porte, três de médio porte e três de pequeno porte), e as sedes de três entidades negras (ONGs que têm como público alvo a comunidade negra ou afrodescendente). Em cada visita, realizei uma entrevista com um funcionário da empresa, no geral gerentes de recursos humanos ou de responsabilidade social que mantinham uma relação direta com as políticas de valorização da diversidade praticadas pela empresa. Só em quatro dos casos (em duas empresas e em duas ONGs) foram realizadas mais de uma visita, variando segundo o grau de profundidade da pesquisa ( $v$. LORENZO, 2010). Os casos foram selecionados seguindo o tradicional método "bola de neve". No início, grande parte dos contatos foi facilitada pelo Instituto Ethos de Empresas e Responsabilidade Social, pois muitas dessas empresas eram associadas a este. Posteriormente, os próprios entrevistados foram indicando outras 
pessoas relevantes no assunto e passíveis de serem entrevistadas. No total (incluindo o caso do Geração XXI) , foram realizadas 37 entrevistas, todas gravadas e transcritas.

A pesquisa de campo do caso Geração XXI aconteceu na última fase do estudo, entre maio e julho de 2005. Nesse período, visitei a sede do projeto duas vezes por semana, durante as quais mantive conversações com os coordenadores e beneficiários do projeto e consultei fontes secundárias referentes ao ciclo de vida do projeto. Realizei 10 entrevistas em profundidade com jovens beneficiários do projeto, sendo cinco garotas e cinco garotos. O questionário continha perguntas abertas e fechadas e era dividido em três blocos temáticos: "trajetória pessoal", "questões práticas do cotidiano" e "planos de futuro". O propósito do questionário foi entender melhor o mundo da vida dos jovens em relação aos objetivos estratégicos do projeto.

Como mencionado na Introdução, este trabalho inspira-se na teoria da ação comunicativa de Habermas. Com o intuito de avaliar a validade dos discursos registrados ao longo da pesquisa de campo, o texto utiliza-se dos "tipos puros de interação linguisticamente mediada", tal como foram classificados por Habermas (2010), isto é, dos atos de fala imperativos, constatativos, regulativos e expressivos. A vantagem analítica dessa classificação é a ênfase colocada nas interpenetrações que se dão entre perlocuções - imperativos em que um falante pretende mobilizar um ouvinte para realizar uma ação - e ilocuções - proposições afirmativas, confessionais ou valorativas as quais hão de ser aceitas ou rejeitadas (validadas) por um ouvinte. Ao insistir na importância de prestar atenção ao reconhecimento intersubjetivo de pretensões de poder e pretensões de validade, o autor aponta um caminho para o observador empírico, convidando-o a visibilizar as implicações extraverbais - implícitas, indiretas e ambíguas - das sequências dos atos de fala registrados, sejam estes depoimentos individuais ou diálogos. A pragmática formal - "o conhecimento das condições sob as quais um ato de fala pode ser aceito como válido ou rejeitado por um ouvinte" - fica, assim, conectada com a pragmática empírica, "o saber de fundo contingente" dos tipos puros de atos de fala (HABERMAS, 2010, p. 378).

A seguir, são analisados os discursos emitidos pelos diferentes interlocutores do projeto.

\section{"O Geral": vallidando discrursos}

"O Gera", como os jovens beneficiários referiam-se ao Geração XXI, resultou de uma aliança estratégica intersetorial entre Fundação BankBoston, Geledés e Fundação Palmares. A Fundação BankBoston foi criada, em 1999, pelo BankBoston para representar as suas ações de responsabilidade social no Brasil. A missão da Fundação era desenvolver programas sociais, culturais e educacionais em parceria com instituições internacionais, governo, organizações sem fins lucrativos, empresas e universidades.

O Geledés é uma organização sem fins lucrativos, fundada em 1990, em São Paulo, que tem desempenhado um papel muito importante na articulação e avanço das demandas feministas e do movimento negro. Oriundo da luta pela democracia no tempo da ditadura, a principal missão do Instituto é proteger, garantir e expandir direitos de cidadania básicos entre a população negra. O Geledés foi a primeira organização no Brasil a oferecer um serviço SOS Racismo com assistência jurídica às vítimas da discriminação racial. Além disso, o Instituto tem desenvolvido ações seminais que visam capacitar e atender mulheres em situações de violência. O Geração XXI veio representar uma experiência de parceria intersetorial inédita no Brasil. A Fundação BankBoston foi o parceiro formulador e financiador do projeto, o Geledés adotou o papel de gerenciador direto dos programas e ações específicos.

A Fundação Palmares foi fundada em 1988, pelo governo federal, no contexto dos eventos políticos e culturais organizados para a celebração do centenário da abolição da escravatura. Durante algum tempo, a Fundação Palmares foi o principal mediador entre o governo e as organizações ligadas ao movimento negro. No entanto, a ênfase excessiva colocada por esta na preservação dos valores culturais e do patrimônio afro-brasileiro, seguindo os preceitos estabelecidos pelo artigo 215 da Constituição de 
1988, tem se provado ineficiente nos assuntos econômicos e sociais que preocupam a maior parte da população negra hoje (TELLES, 2003). Ao escolher a Fundação Palmares como parceiro do Geração XXI, o Geledés buscou ter o governo federal representado na parceria, tentando, assim, influir nas políticas públicas do governo e abrir canais de diálogo com outras entidades governamentais. Porém, a Fundação Palmares ficou sempre ausente do projeto e, nas poucas ocasiões que o Geledés a contatou, a Fundação se mostrou incapaz de responder às mais simples demandas. Se o Geração XXI tivesse acontecido mais adiante, as coordenadoras do Geledés, provavelmente, teriam procurado a SEPPIR, ou parceiros internacionais estratégicos como a UNESCO.

O Geração XXI iniciou-se de uma maneira um tanto particular. De acordo com um gerente de recursos humanos da Fundação BankBoston, em 1999, o conselho diretivo dos Estados Unidos veio ao Brasil para conhecer os executivos do banco. Quando visitaram a sede do banco em São Paulo, um executivo afro-americano, que formava parte do conselho norte-americano, perguntou: "Por que não têm pessoas de cor no banco?". Como resposta, nesse mesmo ano, em uma visita à sede do banco em Boston, os executivos brasileiros apresentaram uma proposta que eventualmente originaria o Geração XXI.

Inspirada pela ideia da "etnografia multilocal" (MARCUS, 1995), de não presumir a contingencia do local de pesquisa e de seguir (follow) as ramificações do caso etnográfico aonde elas levarem, entrevistei, nos Estados Unidos, o executivo afro-americano que tinha levantado a questão da ausência de negros no banco. 0 entrevistado descreveu o contexto daquela visita como segue:

O Brasil era um país com uma reputação por ter uma sociedade bem integrada no sentido em que as pessoas eram integradas na sociedade como um todo. Porém, eu me senti frustrado, pois não pude enxergar nem se quer uma pessoa que se parecesse comigo nos escritórios do banco. Assim, enquanto as apresentações dos colegas brasileiros estavam acontecendo, perguntei: 'Por que não tem gente de cor trabalhando no banco?'. E a resposta geral foi: 'a gente realmente não presta atenção à questão da cor aqui no Brasil, portanto nunca tínhamos percebido'; 'vocês têm alguma ideia sobre o que poderia ser feito?'. Eles argumentaram que as pessoas de cor não conseguem chegar ao sistema universitário. Portanto, apoiar financeiramente estudantes ao longo das suas carreiras universitárias seria uma abordagem que poderia ajudá-los.

São muitos os que se precipitariam a tachar o depoimento acima como um ato de fala imperativo, ou seja, um caso nítido de coerção norte-americana na adoção de ações afirmativas para negros no Brasil (v. BOURDIEU; WACQUANT, 1999). No entanto, os executivos brasileiros não teriam aceitado as pretensões do colega afro-americano tão rápido se não existisse uma expectativa no governo e em algumas organizações da sociedade civil brasileira para que instituições públicas e privadas se envolvam em iniciativas de promoção da igualdade racial. A forma inesperada como o afro-americano formulou a pergunta de "por que não têm pessoas de cor no banco?" (ato de fala constatativo), num ambiente criado para conversar sobre assuntos financeiros, acabou revelando uma constatação objetiva imediata (a não-existência de "pessoas de cor" no banco) e problematizando o que sempre tinha sido taken for granted pelos executivos brasileiros. O sucesso do afro-americano ao mobilizar os executivos brasileiros para agir no sentido por ele apontado, confirma a premissa de Majone (1989, p. 6-7) de que as escolhas de certas políticas, com muita frequência, não são baseadas em "hard facts", mas em percepções compartilhadas e juízos de valor (afinal, o saber de fundo dos executivos brasileiros de que não havia negros no banco não foi confrontado com dados demográficos sobre o perfil étnico-racial dos funcionários do banco). Deste modo, é mais comum do que se tenderia a imaginar que as parcerias intersetoriais sejam iniciadas por meio de redes de relacionamentos pessoais, principalmente por pessoas que ocupam posições interorganizacionais estratégicas, mais do que por vias institucionais monológicas que não envolvem um pré-reconhecimento intersubjetivo entre as partes.

O executivo afro-americano também pensou que ter bolsas de estágio depois do estudante completar a universidade teria sido um "natural follow" do projeto. No entanto, a questão de recrutar estudantes durante ou depois da universidade causava 
resistência entre os gerentes e executivos do BankBoston, assim como entre outras empresas multinacionais que depois replicaram o Geração XXI, indicando uma rejeição geral em algumas multinacionais de relacionar as ações afirmativas externas à empresa com as práticas de emprego internas. Em definitivo, o Geração XXI era legítimo enquanto "best practice" externa à empresa, restrita ao âmbito da responsabilidade social. Nesse sentido, um gerente da Fundação BankBoston argumentou:

O conceito de responsabilidade social empresarial foi sempre muito vinculado à Fundação e não à Empresa. Temos um misunderstanding nessa questão. Estamos fazendo um esforço enorme para esclarecer que responsabilidade social não é comunidade ou fundação, é 'você gerente' nas suas relações com os funcionários, o que você compra de seus fornecedores, se você cumpre com os códigos de ética e assim por diante. Mas isso ainda não está claro para a maioria dos funcionários.

A disjunção entre corporação e fundação, ou entre local de trabalho e comunidade, comprometeu, de certo modo, a confiabilidade entre os parceiros do Geledés e da Fundação BankBoston. Por exemplo, num documento arquivado pelos coordenadores e coordenadoras do projeto, que registrou as conversas de uma reunião entre os parceiros, o Geledés percebia o fato de o BankBoston não ter uma política de oportunidades para negros como um obstáculo. A reafirmação do gerente da Fundação de que "responsabilidade social não é comunidade ou fundação, é 'você gerente' nas suas relações com os funcionários" (ato de fala regulativo), revela assim distorções comunicativas manipulativas importantes se levada em conta a autoimagem institucional do banco de organização socialmente responsável. Isto é, se o discurso ético de responsabilidade social do BankBoston fosse levado à prática, este deveria considerar o negro como potencial consumidor e contratar cidadãos negros, inclusive quando tais práticas poderiam pôr em risco a lucratividade de curto prazo do banco (v. CARROLL, 1991). Porém, como um gerente de recursos humanos envolvido no Geração XXI corroborou, a valorização da diversidade étnico-racial não era considerada um assunto core na sede brasileira do banco:

Para o Bank of America (matriz do BankBoston nos Estados Unidos), hoje diversidade significa mais do que uma política "nice to have"; é fundamental para a competitividade do negócio. Porque o Bank of America é o maior banco comercial nos Estados Unidos. Nossos clientes lá são muito diversos, hispânicos, negros, asiáticos. No Brasil, não temos tanta diversidade. Tentamos deixar claro que a diversidade não tem a ver só com a cor da pele, mas com pensar de maneiras diferentes e saber como lidar com essas diferenças.

Gerenciar a diversidade é entendido aqui a partir de uma perspectiva de stakeholder, que considera os "grupos minoria" como potenciais clientes e consumidores. Como a afirmação valorativa do gerente do BankBoston revela, é a "gestão da diversidade" entendida como negócio, e não a ação afirmativa entendida como tratamento preferencial de grupos minoria, o paradigma hegemônico na sede do banco nos Estados Unidos. No Brasil, o BankBoston era um banco elitista, já que era preciso provar que se tinha uma renda mensal de, no mínimo, $\mathrm{R} \$ 4$ mil reais para se tornar cliente do banco. Como no Brasil, segundo os dados elaborados por Henriques (2001), baseados no censo de 2000, a renda per capita dos brancos era então quase $20 \%$ mais alta do que a renda per capita dos negros (pardos e pretos agregados), portanto, são poucos os negros que se tornariam clientes do BankBoston. Contudo, a questão da eticidade implícita no dilema de se o BankBoston Brasil - assim como outras empresas que atuam no Brasil - devia ou não abordar o negro como cliente/consumidor nunca foi debatida abertamente no contexto de parceria do Geração XXI .

A equipe interinstitucional do Geração XXI, por outro lado, tentou legitimar em todo momento uma definição de ação afirmativa coerente com o plano de direitos humanos do governo. O conceito foi definido dentro de um marco legal plural que levava em conta a Convenção 111 da Organização Internacional do Trabalho - OIT sobre discriminação no emprego e nas ocupações, junto com os artigos 5 e 23 da Constituição de 1988, sobre racismo e marginalização social, respectivamente. Os coordenadores e coordenadoras do projeto divulgaram o Geração XXI como a primeira ação afirmativa para jovens negros do Brasil, definindo o conceito como: 
(...) qualquer política que vise favorecer grupos socialmente discriminados por motivo de sua raça, religião, sexo e etnia e que, em decorrência disto, experimentam uma situação desfavorável em relação a outros segmentos sociais.

Os jovens selecionados para o Geração XXI procediam todos de bairros pobres de São Paulo. Os candidatos potenciais foram procurados em escolas públicas. O processo de seleção seguiu os seguintes critérios: ser negro, ter entre 13 e 15 anos, estar cursando a sétima série em 1998, ter um bom desempenho escolar e ser proveniente de famílias com renda per capita entre dois e três salários mínimos. O processo de seleção, no entanto, foi questionado em várias ocasiões (v. SILVA, 2003). De acordo com a equipe do projeto, durante a primeira fase de seleção percebeu-se que:

(...) as escolas haviam indicado jovens que, pelo seu fenótipo, reiteravam critérios seletivos discriminatórios que tendem a privilegiar as pessoas negras cujo fenótipo distancia-se do africano e aproxima-se do modelo branco ocidental. Passou-se para uma segunda fase da seleção com esse critério fenotípico reforçado (...) para selecionar jovens negros que não deixassem dúvida de que eram negros.

Para tanto, a equipe de seleção dos candidatos do Geração XXI passou a identificar os chamados "negros de ocasião", aqueles que se autodeclaram negros só para se beneficiar de uma ação afirmativa (SILVA, 2003). A valorização do "modelo branco ocidental", confirmada pelas professoras nas escolas públicas foi, assim, questionada pelas interlocutoras do Geledés que, consensualmente, acordaram selecionar jovens negros cujo fenotípico se aproximasse do africano. Vale salientar, contudo, que, embora a busca de candidatos que se aproximassem do fenótipo africano, como a equipe do Geração fez, fosse, sem dúvida, consistente com a formulação de uma ação afirmativa para negros, tal estratégia não resolve de maneira definitiva a questão da ambiguidade da identidade mestiça, tão presente na sociedade brasileira. Desde o ponto de vista da pragmática, a identidade é uma pretensão de verdade validada em situações naturais de fala. Digamos que - e isto é válido para qualquer processo seletivo que envolva discriminação positiva de grupos específicos - o ato autodeclaratório da identidade étnico-racial de um indivíduo depende, em certa medida, do reconhecimento intersubjetivo desta identidade por ambas as partes envolvidas, principalmente quando este acontece em situações de fala face-to-face e em casos ambíguos como o relatado acima. No contexto atual de proliferação de políticas afirmativas destinadas à população negra, a pretensão de negritude daqueles que se distanciam do fenótipo africano (mestiços ou pardos, de acordo com a classificação do IBGE) estaria sempre sujeita a suspeita, pois contradiz a ideologia do branqueamento que marcou os dois séculos passados e de acordo com a qual o último desejo do mestiço seria "passar" por branco "por meio da miscigenação ou da mobilidade social" (MUNANGA, 1999, p.127).

Para alguns beneficiários do projeto, o processo de admissão foi muito competitivo. Eles querem deixar bem claro que, embora tivessem sido beneficiados por uma ação afirmativa, a seleção foi baseada no mérito entre os pares. Na segunda fase do projeto, os estudantes passaram de escolas públicas de ensino fundamental para escolas particulares de ensino médio, com o objetivo de se prepararem melhor para o vestibular. Essa foi, no entanto, uma transição difícil para a maioria, dado o baixo nível de qualidade das escolas públicas de onde procediam. Uma vez que terminaram o ensino médio, todos foram aceitos em universidades particulares, nenhum em universidades públicas:

Eu comecei a ter uma consciência racial mais sólida. Hoje, eu percebo que os negros não são aceitos nas universidades públicas não porque eles não tenham capacidades, mas porque eles encontram muitas dificuldades no caminho. (J ovem do sexo feminino, em 05/07/05).

Eu estudava num lugar onde todo mundo humilhava os professores. Eu não pensava de maneira alguma no meu futuro. A responsabilidade que tivemos que assumir ao mudar para as escolas particulares e ao entrar nas universidades mudou nossas vidas de um modo incrível. (Jovem do sexo feminino, em 07/07/05).

A pretensão de veracidade (sinceridade) dos entrevistados (ato de fala expressivo) desvela vivências às quais eles têm acesso privilegiado. Como as narrativas 
acima revelam, independentemente das certezas ou incertezas que 0 ato declaratório da identidade étnico-racial possa envolver para cada individuo em questão, a inclusão numa ação afirmativa representa um momento de ruptura com o mundo vivido para quem se beneficia dela. Autoevidências e convicções até então inquestionáveis passam a ser mobilizadas. Ao mesmo tempo, os sujeitos distanciam-se uns dos outros uma vez que opiniões individuais são construídas e expressadas na esfera pública.

Quando perguntados sobre o que o termo "ação afirmativa" significava para eles, se bem que todos os jovens entenderam a experiência da ação afirmativa como um processo emancipador e reparador de injustiças passadas, constataram-se dissensos relevantes:

Eu sou a favor das cotas. Eu acho que elas são uma coisa muito positiva, mais uma oportunidade para melhorar o nível educacional do Brasil. (J ovem do sexo feminino, 04/07/05).

Acredito que as pessoas necessitam ter oportunidades, e a cota na universidade é sem dúvida uma oportunidade para o negro, por ter sido marginalizado no passado. Agora, tem um trabalho muito importante que deve ser feito muito antes. Por exemplo, o trabalho que foi feito com a gente no ensino médio é crucial. (Jovem do sexo masculino, em 04/07/05).

Eu sempre pensei que as ações afirmativas são extremamente necessárias como parte de um processo de reparação, embora não para sempre, senão como algo temporário, até as pessoas alcançarem o nível de igualdade e de oportunidades ao menos equivalentes com os outros grupos. (J ovem do sexo feminino, em 05/07/05).

Eu acho que as ações afirmativas estão aumentando e devem continuar assim, embora eu acho que não deveriam estar relacionadas só à cor. (J ovem do sexo feminino, em 07/07/05).

A pretensão de veracidade dos jovens a respeito do significado das ações afirmativas contrasta com os discursos autorreferenciais proferidos pelas instituições parceiras, os quais pré-supõem um participante potencial. Este suposto macrosujeito sociopolítico, com um ponto de vista moral ideal, porém, é na prática um "interlocutor competente" de carne e osso que age em situações de fala aqui e agora. O projeto como um todo pode ser entendido metaforicamente, neste duplo sentido, como uma comunidade comunicativa ilimitada, um processo de interpretação transcendente "aberto a infinitas e possíveis interpretações" (HABERMAS, 2003, p. 33), porém, localizado no tempo e no espaço e voltado a um fim.

No percurso do projeto, foi aguçando-se, cada vez mais, o seguinte problema: como integrar socialmente mundos da vida "pluralizados" uma vez que cresce o risco de dissenso nos domínios da ação comunicativa, motivado pelo discurso e a racionalidade instrumental?

Apesar da esfera pública ser entendida - no sentido habermasiano do conceito - como "uma rede adequada para a comunicação de conteúdos, tomadas de posição e opiniões" (HABERMAS, 2003 p. 92), seria ingênuo acreditar que as estruturas de comunicação dos projetos sociais são naturalmente orientadas ao entendimento mútuo. A necessidade de procedimentos comunicacionais orientados ao consenso ficou evidente quando os beneficiários do projeto foram perguntados sobre como a atuação dos profissionais do projeto poderia melhorar. Embora três deles avaliassem tal atuação como "ótima" e sete como "boa" (entre as opções "ótima", "boa", "regular" ou "ruim"), seis dos entrevistados argumentaram que o projeto tinha problemas de comunicação. Seguem alguns desses depoimentos:

Eu melhoraria a comunicação da gente com a coordenação. No começo, a gente tinha um grau de afinidade maior. (Jovem do sexo masculino, em 06/07/05).

Eu melhoraria só a parte de comunicação entre os integrantes e os parceiros. Acho que uma coisa em que o projeto faliu foi na fusão mesmo dos três eixos do projeto, ou seja, Fundação, Geledés e Geração. Acho que é válido a gente tomar decisões, já que somos os protagonistas do projeto. A gente nunca esteve próximo dos parceiros nos momentos importantes de tomar decisões. A gente tem proposto para ter um conselho participativo dos integrantes do Geração para participar das reuniões que 
eles têm com a Fundação BankBoston (...) mas a verdade é que a gente nem sabe a posição deles. Talvez, seja uma falha de comunicação mesmo. (Jovem do sexo masculino, em 04/07/05).

No início, a gente tinha um sentido de grupo muito forte, e hoje o que a gente tem é o individualismo. Uma opinião de fora agora seria mais válida para a gente. A gente começou a fazer neste ano um plano individual com uma pessoa de fora. Isso foi uma coisa legal, mas não teve continuidade. (Jovem do sexo feminino, em 29/07/05).

Poderia a participação dos jovens nas reuniões dos parceiros (pretensão de poder) ter contribuído para a inclusão de interesses conflituosos na agenda dos parceiros? Sem dúvida. Afinal, como eles argumentaram, ainda que suas demandas não fossem aceitas, pelo menos teriam sido ouvidas. Talvez seja esta uma lição importante a ser aprendida, extensível a outras parcerias intersetoriais: a necessidade de se pensar mais em forças de legitimação dos projetos sociais baseadas na institucionalização de procedimentos comunicacionais orientados ao entendimento mútuo, e menos na implementação de procedimentos instrumentais externos orientados ao êxito institucional ou individual.

Significados compartilhados mais consistentes dos conceitos de diversidade, ação afirmativa e responsabilidade social empresarial poderiam ter sido construídos se situações dialógicas não coercitivas tivessem sido "resgatadas" a partir de um maior engajamento dos jovens nas estruturas político-institucionais da parceria. A institucionalização de procedimentos comunicacionais orientados ao entendimento mútuo poderia ter fortalecido a confiabilidade entre todos os interlocutores do projeto, ter aberto caminhos para a construção de significados compartilhados e propiciado uma maior legitimidade dos argumentos emitidos por aqueles.

O Geração XXI encerrou-se em dezembro de 2007. Entre meados de 2005, que foi o momento da pesquisa, e o final do projeto, existiram algumas mudanças. No final de 2005, a Fundação BankBoston foi absorvida pelo Itaú Social. Houve uma mudança em relação à parceria, mas o projeto continuou e teve o primeiro formando. O projeto chegou, assim, no fim de 2007, com treze bolsistas, sendo quatro deles já formados e os outros com a promessa de continuidade da bolsa pelo Banco I taú e com a possibilidade de fazerem parte do corpo de funcionários do banco, questionando, desse modo, a posição mantida anteriormente pelo BankBoston de não recrutar os beneficiários do projeto durante ou após completar o ensino superior.

\section{Comelrusões}

A teoria da ação comunicativa incita-nos a refletir sobre as condições sob as quais a racionalidade comunicativa pode ser recuperada em uma situação de fala ideal entre interlocutores competentes. A articulação da pragmática formal (tipos puros de atos de fala) com a pragmática empírica (análise de situações naturais de fala) permitiu- nos observar in loco como falantes e ouvintes validam as suas pretensões de poder e de verdade. De modo particular, a análise argumentativa do Geração XXI permitiu- nos vislumbrar alguns conflitos que as políticas afirmativas destinadas à população negra ou afrodescendente vêm encontrando no contexto brasileiro, prestando especial atenção às possibilidades de negociação de significados e de entendimento mútuo nesse contexto político-institucional específico. Corroborou-se que, embora grande parte das políticas afirmativas para negros tenha sido efetivamente implementada graças à influência, intermediação e, em alguns casos, à participação direta das denominadas ONGs negras, algumas dessas organizações continuam a enfrentar conflitos significativos na hora de estabelecerem acordos de longo prazo com seus respectivos parceiros. Principalmente, chama atenção a exigência à qual as ONGs negras veem-se submetidas a ter que esclarecer, reiteradamente, a eticidade das políticas afirmativas toda vez que uma ação afirmativa é formulada ou implementada.

Os principais limites do estudo referem-se, especialmente, a dois aspectos. Em primeiro lugar, o fato do Geração XXI ter sido a primeira ação afirmativa com jovens negros no Brasil restringiu a possibilidade de comparação com outros projetos que 
surgiram depois. Em segundo lugar, ao ter sido o foco da pesquisa a análise das políticas de diversidade e ações afirmativas nos locais de trabalho como um todo, não foi possível aprofundar mais no tema específico das parcerias intersetoriais.

Afinal, sem minimizar a importância de uma boa otimização dos instrumentos técnicos que toda política pública precisa na busca de impactos sociais positivos, a análise argumentativa faz lembrar que é o processo de argumentação e contra- argumentação que muda substancialmente a prática efetiva dessa política. Sugere-se, portanto, que a análise argumentativa seja utilizada com mais frequência como recurso epistemológico para analisar como as políticas públicas, no geral, e as parcerias intersetoriais, em particular, são deliberativamente articuladas. O objetivo final de tal tarefa é desvelar possibilidades de formas democráticas e emancipatórias de comunicação surgirem no interior de sistemas coercitivos.

Rererêêncials

ALMEI DA, G. Verdade e objetividade. Novas considerações sobre a 'teoria consensual' de J. Habermas. Revista Filosófica Brasileira, v. 1, n. 3, p. 9-22, 1985.

ALVES, M.A.; KOGA, N. M. Brazilian nonprofit organizations and the new legal framework: an institutional perspective. Revista de Administração Contemporânea, Edição Especial, p. 213-234, 2006.

ALVES, M. A. et al. Apresentação - Fórum de Organizações Sociais. Revista de Administração de Empresas (RAE ), n. 48, p. 61-63, 2008.

AUSTIN, J. E. Parcerias: fundamentos e benefícios para o terceiro setor. São Paulo: Futura, 2001.

BARBOSA, E. A negação da raça nos estudos organizacionais. In: ENCONTRO ANUAL DA ASSOCIAÇÃO NACIONAL DE PÓS-GRADUAÇÃO E PESQUISA EM ADMI NISTRAÇÃO - ENANPAD, 33., 2009, São Paulo. Anais... São Paulo: ANPAD, 2009.

BASTIDE, R.; FERNANDES, F.. Brancos e negros em São Paulo. São Paulo: Companhia Editora Nacional, 1971.

BOURDIEU, P.; WACQUANT, L. On the cunning of imperialist reason. Theory, Culture \& Society, v. 16, n. 1, p. 41-58, 1999.

BRESSER, L. C. Reforma do estado para a cidadania: a reforma gerencial brasileira na perspectiva internacional. São Paulo: Editora 34, 1998.

CARDOSO, F. H.; IANNI, O. Cor e mobilidade social em Florianópolis. São Paulo: Editora Nacional, 1960.

CARDOSO DE OLIVEIRA, R. Ação indigenista, eticidade e o diálogo interétnico. Estudos Avançados, v. 14, n. 40, p. 213-230, 2000.

CARROLL, A. B. The pyramid of corporate social responsibility: toward the moral management of organizational stakeholders. Business Horizons, v. 42, n. 4, jul./ ago. 1991.

FERNANDES, F. A integração do negro na sociedade de classes. São Paulo: Dominus - Editora da Universidade de São Paulo, 1969. V. I e II..

FISCHER, F.; FORESTER, J. (Ed.). The argumentative turn in policy analysis and planning. Durham: Duke University Press, 1993.

FISCHER, R.M. Estado, mercado e terceiro setor: uma análise conceitual das parcerias intersetoriais. Revista de Administração da Universidade de São Paulo RAUSP, v. 40, n. 1, p. 5-18, 2005.

FLEURY, M. T. Gerenciando a diversidade cultural: experiências de empresas brasileiras. Revista de Administração de Empresas - RAE, v. 4, n. 3, p. 10-25, 2000. 
FREITAG, B. Dialogando com Jürgen Habermas. Rio de Janeiro: Tempo Brasileiro, 2005.

FREYRE, G. Casa-grande e senzala: introdução à historia da sociedade patriarcal no Brasil 46ạ. ed. Rio de J aneiro: Editora Record, 2002. V. I.

GUIMARÃES, A.S. Políticas públicas para a ascensão dos negros no Brasil: argumentação pela ação afirmativa. Afro-Ásia, n.18, p.235-261, 1996.

. Racismo e anti-racismo no Brasil. São Paulo: Editora 34, 1999.

HABERMAS, J. Teoría de la acción comunicativa. Madrid: Editorial Trotta, 2010, 4 ed [1981]. Tomo I, Tomo II.

O papel da sociedade civil e da esfera pública política. In: Direito e democracia: entre faticidade e validade. 2. ed. Rio de Janeiro: Tempo Brasileiro, 2003. p.57-122. V. II.

HASENBALG, C.; SILVA, N. V. Relações raciais no Brasil contemporâneo. Rio de J aneiro: Rio Fundo Editora Ltda, 1992.

HENRI QUES, R. Desigualdade racial no Brasil: evolução das condições de vida na década de 90. Texto para Discussão 807. Rio de Janeiro: IPEA, 2001.

HERINGER, R; FERREIRA, R. Análise das principais políticas de inclusão de estudantes negros no ensino superior no Brasil no período 2001-2008. In: PAULA, M.; HERINGER, R. (Org.). Caminhos convergentes. Rio de Janeiro: Heinrich Böll Stiftung e Actionaid, 2009. p.137-196.

INSTITUTO ETHOS de Empresas e Responsabilidade Social; IBOPE. Perfil Social, Racial e de Gênero das 500 Maiores Empresas e suas Ações Afirmativas. 2003, 2005, 2007, 2010.

JACCOUD, L.B.; BEGHIN, N. Desigualdades raciais no Brasil: um balanço da intervenção governamental. Brasília: IPEA, 2002.

LORENZO, R. A. Untangling the "transnational social": soft affirmative action, human rights, and corporate social responsibility in Brazil". Focaal - Journal of Global and Historical Anthropology, v. 56, p. 49-61, 2010.

MAJONE, G. Evidence, argument and persuasion in the Policy Process. New Haven: Yale University Press, 1989.

MARCUS, G. Ethnography in/of the world system: the emergence of multi-sited ethnography. Annual Review of Anthropology, v.24, p. 95-117, 1995.

MUNANGA, K. Rediscutindo a mestiçagem no Brasil: identidade nacional versus identidade negra. Petrópolis, RJ: Editora Vozes, 1999.

MYERS, A. O valor da diversidade racial nas empresas. Estudos Afro-Asiáticos, v. 25, n. 3, p.483-515, 2003.

NELSON, J.; MEGILL, A.; MCCLOSKEY, D. (Ed.). The rhetoric of human sciences: language and argument in scholarship and public affairs. Madison: University of Wisconsin Press, 1987.

NOLETO, M. J. Parcerias e alianças estratégicas: uma abordagem prática. 2. ed. São Paulo: Instituto Fontes, 2004.

SANTOS, B.S. Democratizar a democracia: os caminhos da democracia participativa. Rio de Janeiro: Civilização Brasileira, 2002.

SIEBENEICHLER, F.B. Jürgen Habermas: razão comunicativa e emancipação. Rio de Janeiro: Tempo Brasileiro, 1989.

SILVA, C. (Org.). Ações afirmativas em educação: experiências brasileiras. São Paulo: Summus, 2003. 
TELLES, E. Racismo à brasileira: uma nova perspectiva sociológica. Rio de Janeiro: Relume Dumará, 2003.

TENÓRIO, F. Gestão social: uma perspectiva conceitual. Revista de Administração Pública, Rio de Janeiro, v. 32, n. 5, p. 7-23, 1998.

TEODÓSIO, A.S.S. Parcerias tri-setoriais na esfera pública: perspectivas, impasses e armadilhas para a modernização da gestão social no Brasil. 2008. Tese (Doutorado) - Escola de Administração de Empresas de São Paulo, Fundação Getulio Vargas, Rio de Janeiro, 2008.

WALTON, D. Informal logic: a hanbook for critical argumentation. Cambridge: Cambridge University Press, 1989.

WEBER, M. Economia e sociedade: fundamentos da sociologia compreensiva. Brasília: Editora da Universidade de Brasília (tradução de Regis Barbosa e Karen Barbosa), 4.ed, 2009.

Artigo recebido em 26/ 10/ 2010.

Última versão recebida em 14/ 09/ 2011.

Artigo aprovado em 16/ 12/ 2011. 